\title{
Developing Instructional Modules on Engineering Ethics
}

\author{
Hillary Hart, O. Christene Moore \\ University of Texas at Austin
}

\section{Introduction}

Many U.S. colleges and departments of engineering are looking at ways to integrate the teaching of engineering ethics and professional responsibility into existing courses. The value of such integration seems obvious: the case studies and examples spring organically from the subject matter of the course, so that thinking about ethics and professional responsibility becomes demonstrably a part of the design or problem-solving process. And yet, what seems "organic" may nonetheless be time-consuming and awkward to develop into full-fledged teaching materials and methods. If he/she is not an ethics "expert," how does an engineering instructor create and use course-specific materials on ethics and professional responsibility?

At the University of Texas at Austin, the College of Engineering is attempting to answer this question by sponsoring a faculty team to develop a series of Web-based teaching modules on topics ranging from research ethics to professional liability. Each module is designed to provide all materials necessary to assess what students already know about the topic, to prepare them for in-class discussion, to offer additional readings and resources, and to engage in follow-up activities. The goal is to create flexible instructional materials that will help instructors incorporate a discussion of ethical issues in their core engineering courses. The modules allow instructors to pick and choose those materials that best suit the contents and timing of their class. Suggested teaching time devoted to the module varies from one class period (with an out-of-class assignment) to several periods (with tests, homework and team presentations).

All materials will be made available on a Web site, part of which can be accessed by students and part of which will be reserved for instructors only. While there are several excellent Web sites on engineering ethics (www.onlineethics.org, www.engr.washington.edu/ uw$\mathrm{pp} / \mathrm{Pepl} /$ Ethics/index.html, and www.nspe.org/ethics/, to name a few), our modules are intended to be more pedagogically oriented. In addition to case studies, for instance, there will be preassessment and follow-up exercises that put that case in a pedagogical context. Our site will also contain an instructor's "manual" with suggestions on how to use the materials, how to fit them into a variety of courses, and how to handle student discussion and team exercises.

The pedagogical hypothesis being tested in this project assumes that engineering faculty teaching core courses will include ethics and professional-responsibility content in their courses more readily if instructional materials are

- more readily available

- technical subject-matter-specific

- adaptable for individual courses and purposes

- flexible in timing and purpose

- diverse in the variety of scenarios, case-studies, and exercises from which to choose. 
In the late summer of 2001, two modules were developed: 1) Research Ethics, and 2) Global and Social Responsibility. This paper describes the development process and analyzes the pilot test of those two modules in two Engineering Communications classes in the fall of 2001.

\section{Module Development}

The modules were developed by first determining the best organizational strategies for the material, not only in the two modules in question but also in future modules. Our conclusion was that each module would have a unifying set of objectives, an assessment tool, and subtopics, or sessions, the number of which would vary depending on the topic. Each session would then include

- a scenario or case study;

- a set of discussion questions; and

- an exercise or activity that might be executed as an in-class assignment or as a homework, supporting the readings.

Finally each module would include at least one follow-up assignment designed to let students extend some of the analysis they had begun in the class discussion and exercises.

This organizational structure was intended to guide the development of every module in the project and hence to make the modules uniform in design.

\section{Creating Objectives}

Our first step with each module was to create a set of pedagogical objectives that would clearly outline the goals of the material. For instance, on the topic of research ethics we established early in the process that our primary goals were two-fold. First, we wanted students to understand the importance of their ethical obligation to credit the work of others. Always a necessary issue to address in writing courses, the problem of plagiarism is compounded by the unprecedented volume of material readily available to students. Second, we wanted to foster our students' ability to distinguish credible sources from others, another challenge that is intensified by the vast resources on the Internet. Both of these goals are imbedded in the practical goal of teaching students to research and write competent, credible research projects themselves. In a similar process we identified our general goals with regards to Global and Social Responsibility. Working within these general underlying principles, we developed a list of objectives to introduce the module to students. Figure 1 below shows a list of our objectives for each module. The objectives are intended to give both instructor and student goals and a standard by which to evaluate their experience of the modules.

\section{Designing Assessment Tools}

The next step in the development process was the creation of an assessment tool for each module to evaluate what students already knew about the topics. For research ethics we created an exercise that asked students to rate several sources on the basis of credibility. For global and social responsibility we asked students to write a short essay discussing the challenges and benefits of working within a global community with colleagues from other cultures. These exercises preface all other material in the module and should, if they are successful, give instructors insight into students' familiarity with the issues at hand. Ideally, the prefatory 
assessment exercise would be complemented by a follow-up assignment that would provide a tool for assessing what students had learned from the material. For the module on research ethics we did create such a follow-up assignment, an analysis of which is presented below.

When you finish this module you should be able to accomplish the following:

\section{Research Ethics}

- Locate relevant information

- Recognize legal and ethical obligations to credit the work of others

- Differentiate between credible and non-credible sources

- Analyze and evaluate sources of information

- Synthesize all credible conclusions and findings found in published work.

Global and Social Responsibility

- Recognize cultural differences

- Identify courses of action in situations where cultural differences play a role

- Identify different points of view

- Assess the broad (global) impact of engineering decisions

- Make informed judgments about what to do in situations where cultural and social differences play a role

\section{Figure 1. Learning objectives for Engineering Ethics modules}

\section{Creating Sessions}

After developing the objectives and assessment tools for each module, we then had to identify the topics to include within each module. For research ethics we divided the module into sessions on three different issues: 1) Crediting the work of others, 2) Credibility of sources, and 3) Presenting valid data. For the module on Global and Social Responsibility we created two sessions: 1) Ethical standards in a global community and 2) The social impact of engineering design. For each of these sessions we created a scenario or located an existing scenario or case study to provide a practical introduction to the complex issues involved in each topic. For instance, the session on credibility of sources includes a scenario from the University of Washington web site that asked engineers to evaluate unsolicited hearsay information received informally. For the session on presenting valid data and the session on ethical standards in a global community we wrote original scenarios. The scenario on ethical standards in a global community involved evaluating the issue of gift-giving in a foreign setting. Figure 2 is the scenario and discussion questions in their entirety.

The goal, with each scenario and case study, was not to indoctrinate students to a particular view of right and wrong, but to introduce them to the complexities of the issues that they may confront as professionals. The scenarios are designed to pose difficult questions that will elicit a variety of responses. If the scenarios and discussion questions accomplish that purpose, instructors should not feel burdened to master the philosophical doctrines that might inform particular approaches to a problem or even the legal standards. One technique we used in the class discussions in fall 2001 to encourage students to analyze different positions was group work. After students had read a particular scenario they would break into groups and each 
group would have the task of addressing particular questions and/or the viewpoints of a specific character in the scenario. Each group would then present a summary of their discussion to the class as a whole. The result was a variety of viewpoints that enriched everyone's evaluation of the issues, not to mention the discussion. Moreover, as students expressed their views, they significantly simplified the task of demonstrating the complexity of the issues.

\section{Golddiggers?}

The day before she was to leave Tashkent, Jane Armstrong was invited to lunch by Vahktioyr Nijinski the president of Nijinski Mining Company. Jane had spent the last three weeks in Uzbekistan collecting information that could help her company, Bronze Age Metal Supply, determine whether Uzbekistan might be an appropriate place to mine gold. Nijinski Mining was a leading competitor in the bid for Bronze Age's business. Two other Uzbek companies were bidding against Nijinski Mining, and a continent away, in Kenya, another contingent of representatives from Bronze Age Metal Supply was collecting competing bids.

Along with his mine manager, Dilbar, Vahktioyr brought his wife, Nazima, who had studied English and was very eager to meet Americans, to the lunch meeting. Jane came with her co-worker, Bruce O'Brien, and Ilhom, the translator she had hired to help with negotiations. As the group was finishing their meal Vahktioyr presented Jane with a suzani, an, intricate, embroidered wall-hanging. Through Ilhom, Vahktioyr asked Jane to deliver this token of Uzbek friendship and hospitality to her CEO in the United States, and then asked his wife to speak for him in English so that they could dispense for a moment with the interpreter. Nazima explained in halting English to the Americans that a suzani is a traditional Uzbek craft that is passed on from one generation to the next so that each successive generation can elaborate on the initial design. This particular suzani, she told them, was more than 100 years old; five generations of women had contributed to its splendor. Nazima went on to say that she and Vahktioyr hoped that when this suzan was displayed in the United States, it would enlighten Americans about the culture and art of Uzbekistan. Jane accepted the gift and expressed her gratitude on behalf of her company. After the lunch Bruce O'Brien told Jane that she committed a serious breach of ethics and would have to return the gift. Jane argued that the gift did not constitute a bribe; it was simply a demonstration of national pride.

Is it proper for Jane to accept the suzani or is Bruce right?

Do you see a conflict of interest in the scenario for Jane or Bruce?

Does the NSPE Code of Ethics shed any light on what to do here?

Do US legal obligations hold firm in foreign countries?

What are the cultural ramifications of refusing the gift?

How do you weigh the legal, cultural, and social values at conflict in this scenario?

Figure 2. Scenario and study questions for session on ethical standards in the global community 
To accompany each scenario or case study we identified readings that would elaborate on the issues introduced in class discussion. The readings, in some cases, are tied directly to exercises and follow-up assignments, but for the most part they are optional resources and not necessary to the completion of the session. Each session also includes at least one exercise which relates to the scenario or case study.

\section{Follow-up Assignments}

Each module concludes with a follow-up assignment that is designed to encourage students to expand on some of the analysis they have begun in discussion. For instance the follow-up assignment that accompanies the module on Global and Social Responsibility asks students to identify a design issue in engineering and analyze its social relevance.

\section{Assessment Results}

In the fall of 2001, the accompanying Web site had not yet been completed, so, although students read some Web-based readings, all materials were delivered via standard means - print handouts and homework assignments. Assessment of the modules' effectiveness thus far does not, therefore, include the Web component. Also, for various reasons, pre-assessment was not done for the Global Ethics module, so we cannot measure the module's effectiveness in getting students to think more deeply about ethical challenges in their future work with international clients. In the final homework assignment, however, many students did a great job of analyzing the technical and social significance of various engineering innovations, from the use of nuclear power to handicapped accessibility on the University of Texas campus.

For the Research Ethics module, we did implement a pre and a post-assessment set of questions. Before discussing research strategies at all, we asked students in class to rate a set of published sources of information as to their credibility. Many of these sources were Web-based because we were particularly interested in how students evaluate their most accessible sources of information. (The sites were chosen to represent a cross-section of the way scientific information is presented on the Web - our purpose is not to make judgments about the sites' relative value). After reading the scenarios and participating in class discussions on two issues - the importance of giving credit for previous work on a subject and strategies for evaluating the credibility of electronic sources - students were then asked to take the list home and rate the same Web sites after looking at them. Here is the list of sites duplicated in the two assessments:

http://www.greenpeace.org/

(Greenpeace's URL)

http://www.epa.gov/globalwarming/

(The EPA's page on global warming)

www.sciam.com/2000/0800issue/0800epstein.html

(Scientific American article on global warming)

http://www.ucsusa.org/warming/

(The Union of Concerned Scientists on global warming) 
http://www.globalwarming.net/gwnew/default.asp

(Global Warming International Center The 12th Global Warming International Conference and Expo CAMBRIDGE, UK April 8-11th, 2001)

http://www.megastories.com/warming/bangla/intro.htm

(An article about the effect of global warming on Bangladesh)

www.skepticism.net/global_warming/

(Links to articles skeptical of environmentalists' claims)

http://www2.msstate.edu/ krreddy/glowar/glowar.html

(Global Warming International Center maintained at Mississippi State University)

The results were interesting, first of all because students were pretty perceptive right off the bat, and secondly because they became more unanimous in their ratings the second time around. In one large Technical Communication class, about 72 students completed the in-class assignment on September 12 and about 67 did the homework on September 24. The sites deemed most credible were the same for both assignments (the EPA site and the Scientific American article), but the gap widened considerably: 36 and 30 voting for the two sites, respectively, the first time around, and 58 and 20 the second. The students had initially been impressed by the name of the well-known magazine, but when they looked at the sites and evaluated graphics and references and modes of presenting information, they apparently decided the government site was most credible.

For the least reliable site, they initially chose the Skepticism site but after investigation chose the Megastories site (36 to 19 vs. 29 to 40). We do not have data to support this explanation, but we think that although the word "skepticism" was a negative concept for them initially, when they looked at the site they decided that at least the sources of information were made clear (as opposed to the Megastories site). Figure 3 shows their choices of most and least reliable sites before and after class work.
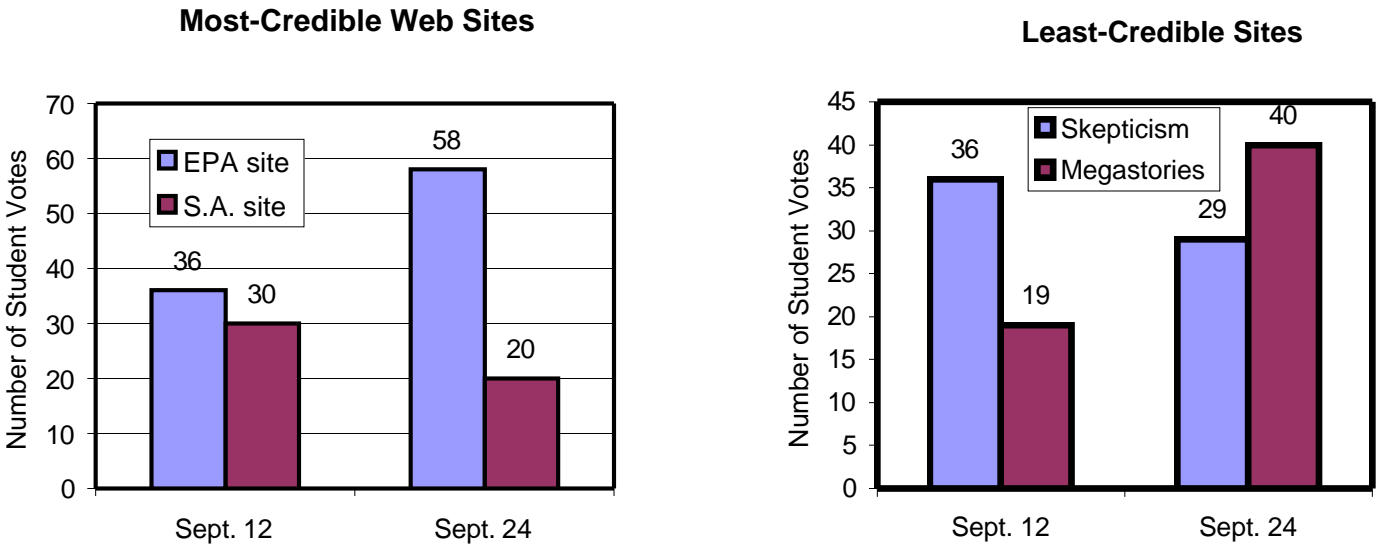

Figure 3. Most and least credible Web sites as determined by students before and after class discussion in September 2001 (S.A. is Scientific American). 
From the numerical data above and from the comments on their homework assignments, it is clear that students used class discussion to deepen and refine their thinking about what constitutes reliable information.

These two ethics modules will be tested again in the Spring semester along with their accompanying Web site and an Instructor's guide.

\section{Future Evaluation and Dissemination}

As modules are completed for each topic, we will test them in a process similar to the one described in this paper. Right now, the missing component for all our modules is an Instructor's Guide for each that will provide pedagogical explanations and practical alternate applications for use in the classroom, as homework, and in discussions. We anticipate completing these guides before the fall 2002 semester so that we can have all modules tested by the end of the fall. Test results will provide formative evaluation that enables us to refine the models. We have chosen Prometheus as the local Web delivery tool for these modules because that software is a course tool that incorporates modules designed to be shared. Since we want to test locally at first, this tool allows easy access by UT Engineering faculty.

By January 2003, we should be ready to disseminate these modules on a wider basis by setting up an Ethics Web site on our College server. We still must iron out the details of how this site should be designed and how to provide different content for different users (faculty and students) around the world.

\section{Conclusion}

We are continuing to develop new modules on engineering ethics and professional responsibility. By the end of the Spring semester, modules on several topics, including safety, intellectual property, and engineering communication, will be completed. While the modules discussed in this paper were designed specifically for Engineering Communication courses, the new modules will be geared for engineering courses with more technical content. Our goal is to enable faculty to include professional responsibility in their courses in a way that makes it relevant to their topic of study but which does not require instructors to completely overhaul their existing curricula or take up philosophy as a new academic field of study. Our observation from our limited experience over one semester is that students are engaged in the topics of discussion and that their analytical capabilities are challenged and encouraged by the material. Although the project is in the beginning stages and therefore difficult to evaluate we believe the initial data indicate that the modules will be a useful tool to both faculty and students.

HILLARY HART, Ph.D., teaches graduate and undergraduate courses in Engineering Communication and Advanced Technical Communication in the Department of Civil Engineering at the University of Texas at Austin.

CHRISTENE MOORE is a Sr. Lecturer in the Department of Mechanical Engineering at the University of Texas at Austin, where she has taught Engineering Communication since 1993. 